\title{
Fertilidade química de solo sob pastagens formadas com diferentes espécies nativas e com Brachiaria decumbens manejadas com queimadas anuais
}

\section{Soils chemical fertility in pastures formed by native species and Brachiaria decumbens managed with annual fire}

\author{
João Tavares Filho ${ }^{1 *}$; Rogério Resende Martins Ferreira ${ }^{2}$; Vinícius Martins \\ Ferreira $^{3}$
}

\begin{abstract}
Resumo
O objetivo deste trabalho foi estudar a fertilidade química do solo sob pastagens submetidas a mais de 10 anos a diferentes manejos com diferentes níveis tecnológicos. O estudo foi realizado em 4 áreas: 1) área com 12 anos de pastagem nativa com queimada a cada três ou quatro anos; 2) área com 12 anos de pastagem nativas e Brachiaria decumbens, com queimada a cada dois ou três anos; 3) área com 13 anos de pastagem nativa manejada com queimadas anuais e 4) área com 10 anos de pastagem de Brachiaria decumbens, manejada com adubação e calagem de $4 \mathrm{em} 4$ anos, sem uso de queimadas. Nessas áreas foram coletadas 10 amostras de solo de forma inteiramente casualizada, nas profundidades de $0-5 ; 5-10 ; 10-15 ; 15-20$ e $20-30 \mathrm{~cm}$, para determinação do $\mathrm{pH}_{\mathrm{H} 2 \mathrm{O}}, \mathrm{CTCpH}_{7,0}, \mathrm{~V} \%, \mathrm{~m} \%$, teor de $\mathrm{P}, \mathrm{K}, \mathrm{Ca}+\mathrm{Mg}$ e matéria orgânica. A comparação de médias entre tratamentos, esta foi feita pelo teste $t$-Student $(\mathrm{p}=0,05)$. Os resultados permitiram concluir que o manejo pastagem de Brachiaria decumbens foi o que apresentou os melhores resultados quanto aos atributos de solo analisados. Os manejos de pastagem nativa com queimada a cada dois anos e pastagem formada por mistura de espécies nativas com Brachiaria decumbens e queimada a cada três anos não apresentaram diferenças quanto aos atributos de solo analisados. $\mathrm{O}$ manejo pastagem nativa com queimadas anuais provocou os menores valores de matéria orgânica.
\end{abstract}

Palavras-chave: Atributos químicos, fertilidade do solo, cambissolo

\begin{abstract}
The aim of this paper was to study the chemical fertility of soils under pastures submitted to more than 10 years to different managements with different levels of technology. The study was conducted in four areas: 1) area with 12 years of native pasture with burning every three or four years, 2) area with 12 years of native and Brachiaria decumbens pasture with burning every two or three years, 3) area with 13 years of native pasture managed with annual burning and 4) area with 10 years of Brachiaria decumbens pasture, fertilizing and liming every 4 years, without burning. These areas were collected 10 soil samples from completely random, at depths $0-5,50-10,10-15,15-20$ and 20 to $30 \mathrm{~cm}$ for determination of $\mathrm{pHH} 2 \mathrm{O}, \mathrm{CTC}_{\mathrm{pH} 7,0}, \mathrm{~V} \%, \mathrm{~m} \%$, the $\mathrm{P}, \mathrm{K}, \mathrm{Ca}+\mathrm{Mg}$ and organic matter. The comparison among treatments was done by Student-t test $(\mathrm{p}=0.05)$. The results showed that the Brachiaria decumbens management showed the best results regarding the analyzed soil attributes. The managements native burned every two years, and a mixture of native and Brachiaria decumbens and burned every three years, showed no
\end{abstract}

\footnotetext{
1 Prof. Dr. do Curso de Pós Graduação em Agronomia da Universidade Estadual de Londrina, UEL/CCA/AGR, Cx. Postal 6001, CEP: 86051-990, Londrina, PR. E-mail: tavares@uel.br

2 Eng ${ }^{\circ}$ Agr $^{\circ}$ Dr., Projeto Maria de Barro/Recuperação Ambiental. E-mail: rogerioferreir@yahoo.com.br

3 Eng ${ }^{\circ}$ Agr $^{\circ}$ Msc., responsável pelo projeto Maria de Barro. E-mail: mariadebarro.crides@yahoo.com.br

*Autor para correspondência
} 
differences in the soil analyzed attributes. Native pasture management with annual burning caused the lowest values of organic matter.

Key words: Soil chemical attributes, soil fertility, organic matter, eutrochrept

\section{Introdução}

A necessidade crescente de aumento da produção agrícola tem provocado uma exploração intensa dos solos pelas atividades agrícolas, muitas vezes de forma inadequada, resultando em degradação do mesmo com diminuição de sua fertilidade física, química e biológica. Esses problemas são tanto maiores, quanto maiores forem as limitações ao uso agrícola (baixa fertilidade, solos arenosos, maior suscetibilidade á erosão, impedimentos mecânicos) e mais intensas as técnicas empregadas na exploração agrícola (MÜLLER et al., 2001; FERREIRA; TAVARES FILHO; FERREIRA, 2010).

A partir dos anos de 1960 houve expansão das áreas com pastagens cultivadas no Brasil para atender a crescente demanda por produtos de origem animal no país. Todavia, a perda gradual da capacidade produtiva dessas pastagens tem sido uma constante nesses ecossistemas, principalmente em áreas de baixo nível tecnológico. Partindo-se da informação de que no Brasil existem cerca de 200 milhões de hectares de pastagens, e que $20 \%$ dessa área é constituída de pastagens degradadas apenas do gênero Brachiaria, esta degradação passa a ser um fato considerável devido ao prejuízo econômico na produção animal (BONFIM-SILVA, 2009).

Na Bacia Alto Rio Grande (MG), predomina a exploração agropecuária em sistema de pastagem nativa extensiva com baixa produtividade sob Cambissolo derivado de rochas pelíticas pobres, os quais apresentam limitações à sua utilização agrícola como alta susceptibilidade à erosão, baixa capacidade de armazenamento de água, baixa fertilidade natural, além de impedimentos à mecanização devido ao relevo (HORTA, 2009; FERREIRA; TAVARES FILHO; FERREIRA, 2010). Esses aspectos, aliados à pouca cobertura proporcionada pela vegetação nativa predominante nas pastagens da região, indicam que o manejo desses solos requer cuidados especiais para não aumentar os riscos erosão.

Entretanto, nessa região, dentre as práticas de manejo das pastagens, a queima anual constitui-se em uma prática largamente adotada, quase dominante, sendo seu uso defendido por ser uma prática que visa a limpeza da pastagem, em substituição à roça, por causa do baixo custo operacional, bem como, para controle de pragas e promover a renovação das pastagens através da renovação de partes vegetativas não consumidas e lignificadas do extrato herbáceo, provocando um rebrote de melhor qualidade e controle do crescimento de arbustos (BARROSO FILHO, 2007). Porém, se de um lado a queimada facilita a vida de parte dos agricultores trazendo benefícios em curto prazo, de outro, ela pode afetar negativamente a biodiversidade (microorganismos do solo e eliminação dos inimigos naturais das pragas), aumentar a erosão do solo, reduzir a qualidade do ar e provocar danos ao patrimônio público e privado (LOUZADA; MACHADO; BERG, 2003; BARROSO FILHO, 2007). Além disso, a queimada reduz o teor de matéria orgânica do solo, a qual pode ser vista como um atributo chave quando se pretende avaliar a qualidade do solo, uma vez que tem importante papel no fornecimento de nutrientes e na melhoria das propriedades físico-hidricas e químicas do solo (BERNOUX et al., 1999; DONKOR et al., 2002). Dessa forma, o objetivo deste trabalho foi estudar a fertilidade do solo sob pastagens submetidas a mais de 10 anos a diferentes manejos com diferentes níveis tecnológicos.

\section{Material e Métodos}

O estudo foi realizado em áreas de pastagem sobre Cambissolo Háplico, inseridas na bacia "Alto Rio Grande (MG)", município de Nazareno (MG), cuja posição geográfica é $21^{\circ} 22^{\prime}$ de latitude sul e $44^{\circ} 61^{\prime}$ de longitude oeste e altitude média de $935 \mathrm{~cm}$. O clima da 
região é tropical de altitude, com invernos frios e secos e verões quentes e úmidos, do tipo Cwa, a temperatura média anual varia de $18^{\circ} \mathrm{C}$ a $19^{\circ} \mathrm{C}$ e a precipitação média anual varia de 1.200 a $1.500 \mathrm{cmm}$ por anos (MARQUES; CURI; LIMA, 2002).

Para o estudo, foram selecionadas quatro áreas, cujas características físicas e químicas são apresentadas na (Tabela 1), sobre Cambissolo, com diferentes manejos de pastagem, comuns na região. As áreas selecionadas foram: - área 1 (PN): área com 12 anos de pastagem nativa com Diandrostachya chrysotrix, Paspalum plicatulum e Andropogon leucostachyus, com queimada a cada dois anos para limpeza do pasto. Uma última queimada foi executada três anos antes do início do presente trabalho; - área 2 (PD): área com 12 anos de pastagem formada por uma mistura de espécies nativas como Diandrostachya chrysotrix, Paspalum plicatulum e Andropogon leucostachyus com Brachiaria decumbens com queimada a cada três anos para limpeza do pasto. Uma última queimada foi executada dois anos antes do início do presente trabalho; - área 3 (PQ): área com 13 anos de pastagem nativa (Diandrostachya chrysotrix, Paspalum plicatulum, Andropogon leucostachyus) manejada com queimadas anuais e, - área 4 (PR): área com um sistema implantado a 10 anos com uma pastagem de Brachiaria decumbens, manejada com adubação e calagem na implantação da pastagem e outras duas vezes - 4 e 8 anos após a sua implantação segundo análise de solo; sem uso de queimadas para limpeza do pasto.

Tabela 1. Características físicas e químicas de Cambissolo sob pastagem com diferentes manejos ${ }^{(1)}$.

\begin{tabular}{|c|c|c|c|c|c|c|}
\hline \multirow{2}{*}{$\begin{array}{l}\text { Tipos de } \\
\text { pastoreio } \\
\text { extensivo* }\end{array}$} & \multirow{2}{*}{$\begin{array}{l}\text { Prof. } \\
\text { (m) }\end{array}$} & \multicolumn{3}{|c|}{ Textura $\left(\mathrm{g} \mathrm{kg}^{-1}\right)$} & \multirow[t]{2}{*}{ Silte/Argila } & \multirow{2}{*}{$\begin{array}{r}\mathrm{Dp}^{(2)} \\
\left(\mathrm{Mg} \mathrm{m}^{-3}\right)\end{array}$} \\
\hline & & Areia & Silte & Argila & & \\
\hline \multirow[t]{2}{*}{ Área 1 (PN) } & $0-15$ & 390 & 220 & 390 & 0,56 & 2,67 \\
\hline & $15-30$ & 380 & 230 & 390 & 0,59 & 2,64 \\
\hline \multirow[t]{2}{*}{ Área 2 (PD) } & $0-15$ & 370 & 230 & 400 & 0,57 & 2,68 \\
\hline & $15-30$ & 390 & 240 & 370 & 0,65 & 2,65 \\
\hline \multirow[t]{2}{*}{ Área 3 (PQ) } & $0-15$ & 360 & 240 & 400 & 0,60 & 2,69 \\
\hline & $15-30$ & 340 & 260 & 400 & 0,65 & 2,70 \\
\hline \multirow[t]{2}{*}{ Área 4 (PR) } & $0-15$ & 390 & 230 & 380 & 0,60 & 2,65 \\
\hline & $15-30$ & 360 & 250 & 390 & 0,64 & 2,64 \\
\hline
\end{tabular}

(1)PN (pastagem nativa com queimada a cada dois anos); PD (pastagem formada por uma mistura de espécies nativas com Brachiaria decumbens e queimada a cada três anos); PQ (pastagem nativa com queimadas anuais); PR (pastagem de Brachiaria decumbens, sem uso de queimada).

${ }^{(2)}$ Densidade de partículas.

No centro de cada área, visando evitar efeitos de borda, demarcou-se uma "sub-área" com 2 ha onde foram coletadas 10 amostras de solo de forma inteiramente casualizada, nas profundidades de 0 $5 ; 5-10 ; 10-15 ; 15-20$ e $20-30 \mathrm{~cm}$, perfazendo, portanto, um total de 50 amostras por manejo, para determinação, conforme Embrapa (1997) das seguintes variáveis: $\mathrm{pH}_{\mathrm{H} 2 \mathrm{O}}$, capacidade de troca de cátions a $\mathrm{pH}_{7,0}$, saturação em bases e por alumínio, teor de fósforo, potássio, cálcio mais magnésio e matéria orgânica do solo.

Os resultados foram apresentados na forma gráfica, em valores médios (média de 10 repetições por profundidade) e foi calculado, para cada profundidade dentro de cada manejo, o intervalo de confiança a 95\%. A comparação de médias entre tratamentos, quando necessária, foi feita pelo teste $t$-Student $(\mathrm{p}=0,05)$. Posteriormente, para verificar 
de forma conjunta a fertilidade química do solo nos diferentes manejos em relação à referência adotada do manejo que apresentou os melhores resultados, foram construídos gráficos radiais em relação aos valores de $\mathrm{pH}_{\mathrm{H} 2 \mathrm{O}}$, capacidade de troca de cátions $\left(\mathrm{CTCpH}_{7,0)}\right.$, saturação em bases (V) e por alumínio $(\mathrm{m})$, teor de fósforo $(\mathrm{P})$, potássio $(\mathrm{K})$, cálcio $(\mathrm{Ca}) \mathrm{e}$ magnésio $(\mathrm{Mg})$ e matéria orgânica $(\mathrm{MO})$.

\section{Resultados e Discussão}

Os valores médios e intervalo de confiança (95\%) dos atributos químicos do solo $\left(\mathrm{pH}, \mathrm{CTC}_{\mathrm{pH} 7}, \mathrm{~V} \% \mathrm{e}\right.$ $\mathrm{m} \%$ ) determinados para os diferentes manejos nas cinco profundidades amostradas são apresentados na (Figura 1). Em relação ao $\mathrm{pH}$ em água, o manejo pastagem de Brachiaria decumbens, sem uso de queimada possui o maior valor e, quando da comparação dos manejos dois a dois pelo teste $t$-Student, verificou-se que a pastagem nativa com queimada a cada dois anos, pastagem formada por uma mistura de espécies nativas com Brachiaria decumbens e queimada a cada três anos e pastagem nativa com queimadas anuais não diferem entre si, porém diferem de pastagem de Brachiaria decumbens, sem uso de queimada para o nível de $5 \%$ de probabilidade entre $0-10 \mathrm{~cm}$ de profundidade e posteriormente, entre $15-30 \mathrm{~cm}$, não existe mais diferença entre os manejos. $\mathrm{O}$ uso de queimadas para reforma do pasto não causou diferença de $\mathrm{pH}$ entre os manejos (pastagem nativa com queimada a cada dois anos, pastagem formada por uma mistura de espécies nativas com Brachiaria decumbens e queimada a cada três anos e pastagem nativa com queimadas anuais, pois, segundo Fernandes e Fernandes (2002), o pH aumenta nos primeiros meses após a queimada, provavelmente devido ao efeito das cinzas, que reduzem temporariamente os teores de $\mathrm{Al}$ e de ácidos orgânicos, e tende a cair ou estabilizar-se próximo aos níveis anteriores à queimada, sendo que esse efeito ocorre normalmente nas camadas mais superficiais do solo, entre 0- 10 $\mathrm{cm}$, como foi verificado no presente.
Os maiores valores de $\mathrm{pH}$ na superfície do solo do manejo pastagem de Brachiaria decumbens, sem uso de queimada (Figura 1), pode ser função da maior quantidade acumulada de calcário após a última calagem (dois anos antes do início do presente estudo), indicando que para esse sistema de manejo pastagem de Brachiaria decumbens, sem uso de queimada, os efeitos da calagem como, elevar o $\mathrm{pH}$ do solo, reduzir o $\mathrm{Al}$ e aprofundar $\mathrm{Ca}$ e $\mathrm{Mg}$, ficaram restritos somente à superfície do solo.

Quanto aos valores de $\mathrm{CTC}_{\mathrm{pH} 7,0}$, observa-se na (Figura 1) que os valores são baixos em todos os manejos estudados (inferiores a 7,3 $\mathrm{mol}_{\mathrm{c}} \mathrm{dm}^{-3}$ para pastagem de Brachiaria decumbens, sem uso de queimada, a 4,9 $\mathrm{mol}_{\mathrm{c}} \mathrm{dm}^{-3}$ para pastagem nativa com queimada a cada dois anos, a 5,4 $\mathrm{mol}_{\mathrm{c}} \mathrm{dm}^{-3}$ para pastagem formada por uma mistura de espécies nativas com Brachiaria decumbens e queimada a cada três anos e inferior a 3,3 $\mathrm{mol}_{\mathrm{c}} \mathrm{dm}^{-3}$ para pastagem nativa com queimadas anuais). Entre 0 e $10 \mathrm{~cm}$ de profundidade, existe diferença entre o manejo pastagem de Brachiaria decumbens, sem uso de queimada e os demais manejos (pastagem nativa com queimada a cada dois anos, pastagem formada por uma mistura de espécies nativas com Brachiaria decumbens e queimada a cada três anos e pastagem nativa com queimadas anuais); diferença significativa entre os manejos pastagem formada por uma mistura de espécies nativas com Brachiaria decumbens e queimada a cada três anos e pastagem nativa com queimadas anuais e não ocorre diferença significativa entre os manejos pastagem nativa com queimada a cada dois anos e pastagem formada por uma mistura de espécies nativas com Brachiaria decumbens e queimada a cada três anos. Na profundidade de $15 \mathrm{~cm}$ pastagem de Brachiaria decumbens, sem uso de queimada difere do manejo pastagem nativa com queimadas anuais, mas não difere dos manejos pastagem nativa com queimada a cada dois anos e pastagem formada por uma mistura de espécies nativas com Brachiaria decumbens e queimada a cada três anos, enquanto para esta mesma profundidade a pastagem 
nativa com queimada a cada dois anos - pastagem formada por uma mistura de espécies nativas com Brachiaria decumbens e queimada a cada três anos, pastagem nativa com queimada a cada dois anos pastagem nativa com queimadas anuais e pastagem formada por uma mistura de espécies nativas com Brachiaria decumbens e queimada a cada três anos - pastagem nativa com queimadas anuais não diferem entre si. A partir de $20 \mathrm{~cm}$ de profundidade não existe diferença entre os manejos estudados.

Figura 1. Valores médios e intervalo de confiança $(95 \%)$ do $\mathrm{pHH} 2 \mathrm{O}$, da capacidade de troca de cátions $\left(\mathrm{CTC}_{\mathrm{pH} 7,0}\right)$, da saturação em bases $(\mathrm{V})$ e por alumínio $(\mathrm{m})$ do solo determinados para os manejos PN (pastagem nativa com queimada a cada dois anos), PD (pastagem formada por uma mistura de espécies nativas com Brachiaria decumbens e queimada a cada três anos), PQ (pastagem nativa com queimadas anuais) e PR (pastagem de Brachiaria decumbens, sem uso de queimada).
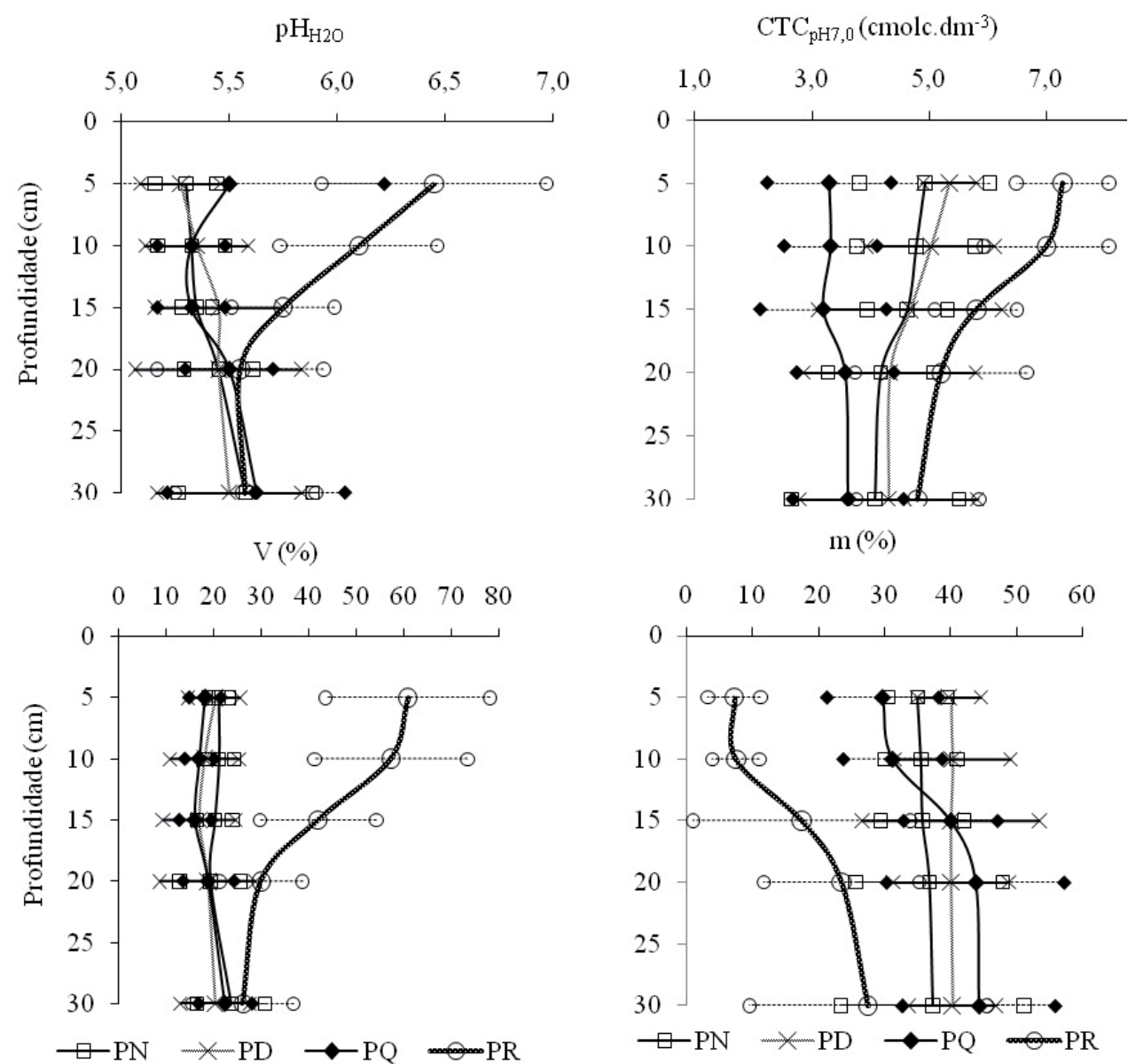

O uso do calcário no manejo pastagem de Brachiaria decumbens, sem uso de queimada, mesmo após dois anos da última aplicação, esta contribuindo para aumentar o valor da CTC, provavelmente devido ao acréscimo de cargas negativas nas partículas do solo, enquanto no manejo pastagem nativa com queimadas anuais o valor da $\mathrm{CTC}_{\mathrm{pH7}, 0}$ foi menor, provavelmente porque a queimada induz, inicialmente, a mineralização da matéria orgânica (SCHACHT et al., 1996), aumentando a disponibilidade de muitos elementos nutricionais (NH4, P inorgânico, Na, Ca, Mg e K) ligados e complexados por essa matéria orgânica. Entretanto, segundo Giovannini e Lucchesi (1997), 
o resultado em longo prazo desse processo é o decréscimo do teor de $\mathrm{MO}$ e da capacidade de troca de cátions (CTC) como constatado nos resultados apresentados anteriormente, na (Figura 1).

Em relação à saturação em bases (V\% - Figura 1), o manejo pastagem de Brachiaria decumbens, sem uso de queimada possui o maior valor e, quando da comparação dos manejos dois a dois, verificou-se que a pastagem nativa com queimada a cada dois anos, pastagem formada por uma mistura de espécies nativas com Brachiaria decumbens e queimada a cada três anos e pastagem nativa com queimadas anuais não diferem entre si, porém diferem de pastagem de Brachiaria decumbens, sem uso de queimada para o nível de 5\% de probabilidade entre $0-15 \mathrm{~cm}$ de profundidade e posteriormente, entre $20-30 \mathrm{~cm}$, não existem mais diferença entre os manejos. Os valores superiores de (V\%) entre $0-15 \mathrm{~cm}$ para o manejo pastagem de Brachiaria decumbens, sem uso de queimada, em relação aos demais manejos, provavelmente se devem ao melhor manejo químico do solo com a aplicação de calcário e adubo e a não utilização de queimada, que sabidamente tende a reduzir a matéria orgânica do solo e, além disso, como nesse sistema o calcário é aplicado a lanço em superfície, não ocorre aprofundamento de partículas de calcário ou dos produtos de sua reação e de bases trocáveis, principalmente $\mathrm{Ca}$ e $\mathrm{Mg}$, para além de $15 \mathrm{~cm}$ de profundidade, tendendo a se restringirem somente até essa profundidade (GASSEN; KOCHANN, 1998). Esses resultados são semelhantes àqueles relatados por Steckling e Ernani (1998) os quais mostraram que os efeitos do calcário ocorrem somente a poucos centímetros abaixo das camadas onde é aplicado ao solo. Além disso, é importante observar que para os demais manejos estudados a saturação por bases não se diferenciou entre eles e tão pouco entre $0-30 \mathrm{~cm}$ de profundidade, indicando que nos casos avaliados, somente o manejo químico pode contribuir com alguma melhoria de fertilidade nesses manejos e solo.

No caso da saturação por alumínio $(\mathrm{m} \%)$, o manejo pastagem de Brachiaria decumbens, sem uso de queimada possui o maior valor (Figura 1) e quando da comparação dos manejos dois a dois, verificou-se que a pastagem nativa com queimada a cada dois anos, pastagem formada por uma mistura de espécies nativas com Brachiaria decumbens e queimada a cada três anos e pastagem nativa com queimadas anuais não diferem entre si, porém diferem de pastagem de Brachiaria decumbens, sem uso de queimada entre $0-10 \mathrm{~cm}$ de profundidade e posteriormente, entre 15 - $30 \mathrm{~cm}$ não existe mais diferença entre os manejos. Se for observado o gráfico relativo à saturação em bases $(\mathrm{V} \%)$, é fácil compreender os resultados da saturação por alumínio, pois, no caso do manejo pastagem de Brachiaria decumbens, sem uso de queimada, o aumento do $\mathrm{pH}$ graças a aplicação de calcário e a não utilização de queimada que reduz a matéria orgânica do solo, aumentaram a saturação em bases e reduziram a saturação em alumínio no solo.

O teor de P (Figura 2) no manejo pastagem de Brachiaria decumbens, sem uso de queimada apresentou maior valor e quando da comparação dois a dois dos manejos, verificou-se que a pastagem nativa com queimada a cada dois anos, pastagem formada por uma mistura de espécies nativas com Brachiaria decumbens e queimada a cada três anos e pastagem nativa com queimadas anuais não diferem entre si, porem diferem de pastagem de Brachiaria decumbens, sem uso de queimada entre $0-15 \mathrm{~cm}$ de profundidade e posteriormente, entre $20-30$ $\mathrm{cm}$, não existiu mais diferença entre os manejos. Os valores de $\mathrm{P}$, encontrados para os manejos pastagem nativa com queimada a cada dois anos, pastagem formada por uma mistura de espécies nativas com Brachiaria decumbens e queimada a cada três anos e pastagem nativa com queimadas anuais em todas as profundidades analisadas, são baixos, praticamente iguais entre si e não estão em acordo com Pietikäinen e Fritze (1995) os quais trabalharam analisando o efeito do fogo nos restos vegetais após o corte de floresta de coníferas; e com Fernadez et al. (1997), os quais trabalharam na floresta atlântica 
e compararam o efeito da queimada no solo; e Fernandes e Fernandes, (2002), que analisaram o efeito de queimadas nas propriedades químicas de solo sob pastagens nativas no MS e encontraram maiores valores de $\mathrm{P}$ que os encontrados neste trabalho.

Figura 2. Valores médios e intervalo de confiança (95\%) do teor de fósforo $(\mathrm{P})$, potássio $(\mathrm{K})$, cálcio $(\mathrm{Ca})+$ magnésio $(\mathrm{Mg})$ e matéria orgânica $(\mathrm{MO})$ do solo determinados para os manejos PN (pastagem nativa com queimada a cada dois anos), PD (pastagem formada por uma mistura de espécies nativas com Brachiaria decumbens e queimada a cada três anos), PQ (pastagem nativa com queimadas anuais) e PR (pastagem de Brachiaria decumbens, sem uso de queimada).
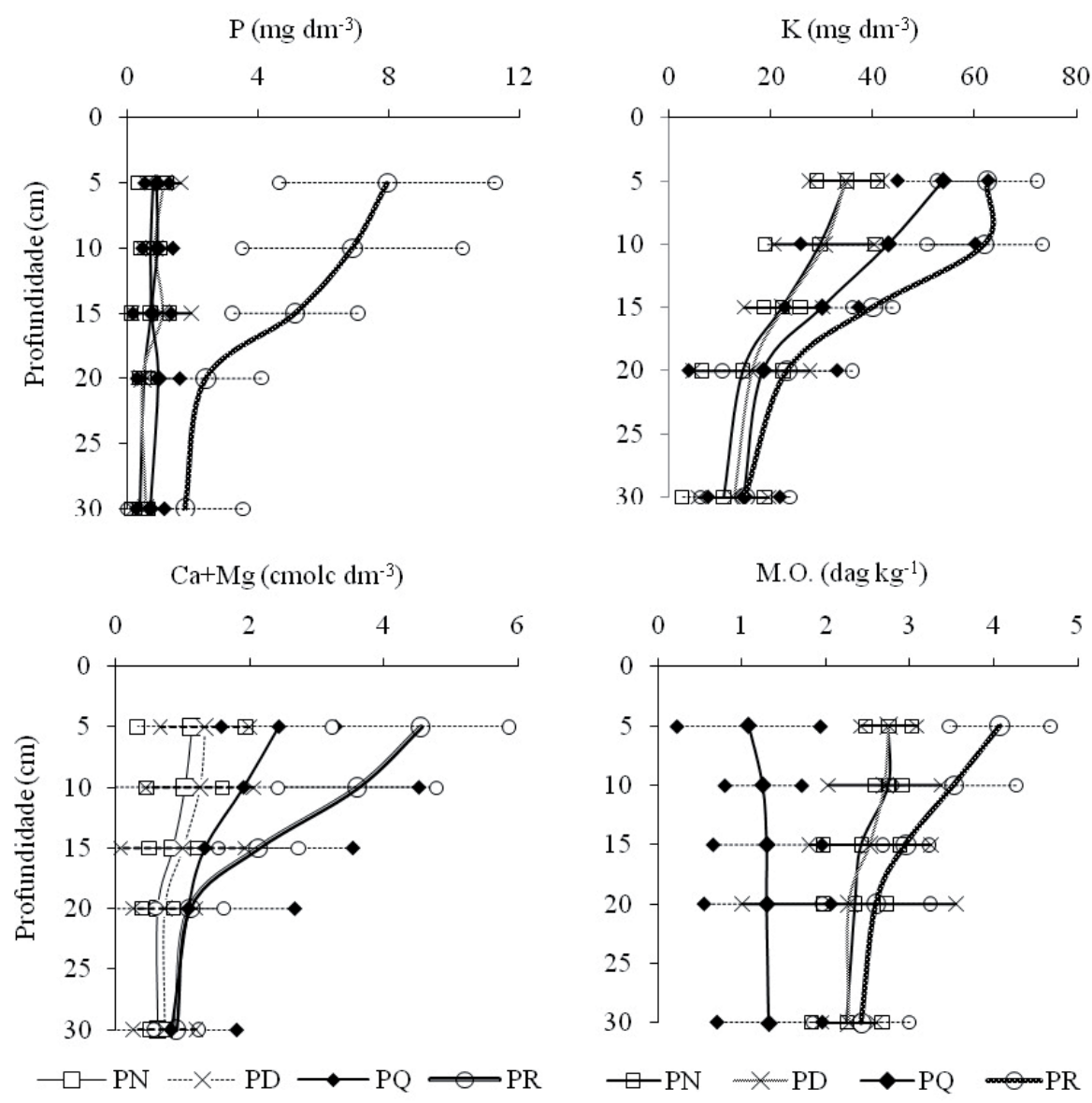

No manejo pastagem de Brachiaria decumbens, sem uso de queimada, o teor de $\mathrm{P}$, principalmente na camada de $0-15 \mathrm{~cm}$, chegou a valores 10 vezes maiores que os teores encontrados nos demais manejos, indicando que o teor de P é função das quantidades aplicadas ao longo dos anos, e seu efeito residual é decorrente da baixa necessidade das culturas, além da fixação do mesmo pelo solo. Além disso, nessas áreas de manejo (pastagem

nativa com queimada a cada dois anos, pastagem formada por uma mistura de espécies nativas com Brachiaria decumbens e queimada a cada três anos e pastagem nativa com queimadas anuais) onde é comum a existência de grandes áreas de solo que ficam descobertas e desprotegidas do impacto das gotas de chuva, por um longo período de tempo, o risco de perdas de nutrientes por erosão é muito grande (HERINGER et al., 2002). 
Em relação aos teores de $\mathrm{K}, \mathrm{Ca}+\mathrm{Mg}$ do solo, verificou-se nos dois casos (Figura 2), para a profundidade de $0-5 \mathrm{~cm}$, que a pastagem nativa com queimada a cada dois anos não difere de pastagem formada por uma mistura de espécies nativas com Brachiaria decumbens e queimada a cada três anos, porem diferem de pastagem nativa com queimadas anuais e pastagem de Brachiaria decumbens, sem uso de queimada os quais não diferem entre. $\mathrm{Na}$ profundidade de $5-10 \mathrm{~cm} \mathrm{o}$ tratamento pastagem nativa com queimadas anuais não apresentou diferença significativa para nenhum dos outros manejos, enquanto o manejo pastagem de Brachiaria decumbens, sem uso de queimada diferiu dos manejos pastagem nativa com queimada a cada dois anos e pastagem formada por uma mistura de espécies nativas com Brachiaria decumbens e queimada a cada três anos, os quais se mantiveram sem diferença significativa. A partir de $15 \mathrm{~cm}$, não mais existiu diferença significativa entre nenhum dos manejos estudados. Verifica-se que os maiores valores são observados em superfície para os tratamentos pastagem nativa com queimadas anuais e pastagem de Brachiaria decumbens, sem uso de queimada, e esses resultados estão em acordo com diversos autores (PIETIKÄINEN; FRITZE, 1995; FERNANDEZ; CABANEIRO; CARBALLAS, 1997; FERNANDES; FERNANDES, 2002). Segundo Schacht et al. (1996) e Pivello e Coutinho (1992), a utilização de queimada anual induz a mineralização da matéria orgânica, com disponibilização de muitos elementos nutricionais, dentre eles o P, K, Ca e o Mg, ligados e complexados por essa matéria orgânica. Já em relação ao manejo pastagem de Brachiaria decumbens, sem uso de queimada, há indicação de que os teores de $\mathrm{K}, \mathrm{Ca}$ $+\mathrm{Mg}$ podem ser função das quantidades de adubo e calcário aplicado no pasto ao longo dos anos.

Quantoaoteordematériaorgânicadosolo(MO)do solo (Figura 2), verificou-se, quando da comparação dois a dois dos manejos, que a pastagem nativa com queimada a cada dois anos não difere de pastagem formada por uma mistura de espécies nativas com
Brachiaria decumbens e queimada a cada três anos, porem diferem de pastagem nativa com queimadas anuais e pastagem de Brachiaria decumbens, sem uso de queimada os quais diferem entre para a profundidade de $0-5 \mathrm{~cm}$. Na profundidade de $5-10$ e $10-15 \mathrm{~cm}$, verificou-se que a pastagem nativa com queimada a cada dois anos, pastagem formada por uma mistura de espécies nativas com Brachiaria decumbens e queimada a cada três anos e pastagem de Brachiaria decumbens, sem uso de queimada não diferem entre si, porem diferem de pastagem nativa com queimadas anuais para o nível de $5 \%$ de probabilidade nessas profundidade de solo. A partir de $20 \mathrm{~cm}$ de profundidade não existiu mais diferença entre os manejos da pastagem. Esses resultados mostram que o teor médio de $\mathrm{MO}$ foi mais afetado pelo uso constante do fogo (manejo pastagem nativa com queimadas anuais), indicando ocorrência de mineralização, com decréscimos significativos em superfície em relação aos demais manejos estudados. Logo, a idéia de que o conteúdo de MO do solo em áreas de pastagem tende a se manter estável, ou então aumentar, depende muito do uso ou não de queimadas, pois, nos manejos onde este uso foi reduzido (pastagem nativa com queimada a cada dois anos, pastagem formada por uma mistura de espécies nativas com Brachiaria decumbens e queimada a cada três anos) o teor de MO foi 2,4 vezes superior ao manejo pastagem nativa com queimadas anuais entre $0-15 \mathrm{~cm} \mathrm{e}$ se manteve praticamente inalterável, porém 1,8 vezes superior ao manejo pastagem nativa com queimadas anuais até a profundidade de $30 \mathrm{~cm}$. Já no manejo onde a queimada é ou ausente (pastagem de Brachiaria decumbens, sem uso de queimada) o teor de MO foi 3,2 vezes superior ao manejo pastagem nativa com queimadas anuais e 1,4 vezes superior aos manejos pastagem nativa com queimada a cada dois anos e pastagem formada por uma mistura de espécies nativas com Brachiaria decumbens e queimada a cada três anos entre $0-15$ $\mathrm{cm}$ e, entre $15-30 \mathrm{~cm}$, o teor de MO foi 2,3 vezes superior ao manejo pastagem nativa com queimadas 
anuais e 1,3 vezes superior aos manejos pastagem nativa com queimada a cada dois anos e pastagem formada por uma mistura de espécies nativas com Brachiaria decumbens e queimada a cada três anos.

Esses resultados estão em acordo com Giovannini e Luchesi (1997), que relatam que o resultado em longo prazo da queimada é o decréscimo do teor de MO e da capacidade de troca de cátions (CTC). Isto é um sério problema, pois, a matéria orgânica do solo é um atributo chave quando se pretende avaliar a qualidade do solo, uma vez que tem importante papel no fornecimento de nutrientes e na melhoria das propriedades físicas do solo. Nas regiões tropicais, sua importância é ainda mais acentuada, pois é a principal responsável pela CTC dos solos, que apresentam principalmente mineralogia caulinítica ou oxídica de baixa atividade. A queima continuada, como no caso do manejo pastagem nativa com queimadas anuais, afetou negativamente o solo em relação ao teor de $\mathrm{MO}$ e CTC e melhorou os teores de $\mathrm{K}$ e $\mathrm{Ca}+\mathrm{Mg}$, estando em acordo com as observações feitas por Schacht et al. (1996) sobre a queimada corrigir o solo e aumentar a oferta de alguns nutrientes no meio.

Considerando que as maiores variações de resultados ocorreram entre $0-20 \mathrm{~cm}$ (Figuras $1 \mathrm{e}$ 2), foram feitos dois gráficos radiais (Figura 3) para verificar de forma conjunta a fertilidade do solo nos diferentes manejos em relação a uma referência, adotada segundo o manejo que apresentou os melhores resultados, ou seja, o manejo pastagem de Brachiaria decumbens, sem uso de queimada, em relação aos valores de $\mathrm{pH}_{\mathrm{H} 2 \mathrm{O}}$, capacidade de troca de cátions $\left(\mathrm{CTC}_{\mathrm{pH} 7,0}\right)$, saturação em bases (V) e por alumínio $(\mathrm{m})$, teor de fósforo $(\mathrm{P})$, potássio $(\mathrm{K})$, cálcio $(\mathrm{Ca})$ e magnésio $(\mathrm{Mg})$ e matéria orgânica (MO).

Figura 3. Diagrama comparativo da fertilidade do solo sob os manejos: Referência (manejo PR - pastagem de Brachiaria decumbens, sem uso de queimada), PN (pastagem nativa com queimada a cada dois anos), PD (pastagem formada por uma mistura de espécies nativas com Brachiaria decumbens e queimada a cada três anos), PQ ((pastagem nativa com queimadas anuais) e, considerando-se os valores obtidos para as camadas de $0-10 ; 10-20 \mathrm{~cm}$ do $\mathrm{pH}_{\mathrm{H} 2 \mathrm{O}}$, da capacidade de troca de cátions $\left(\mathrm{CTC}_{\mathrm{pH} 7,0}\right)$, da saturação em bases $(\mathrm{V})$ e por alumínio $(\mathrm{m})$, do teor de fósforo $(\mathrm{P})$, potássio $(\mathrm{K})$, cálcio $(\mathrm{Ca})$ e magnésio $(\mathrm{Mg})$ e matéria orgânica (MO) do solo.
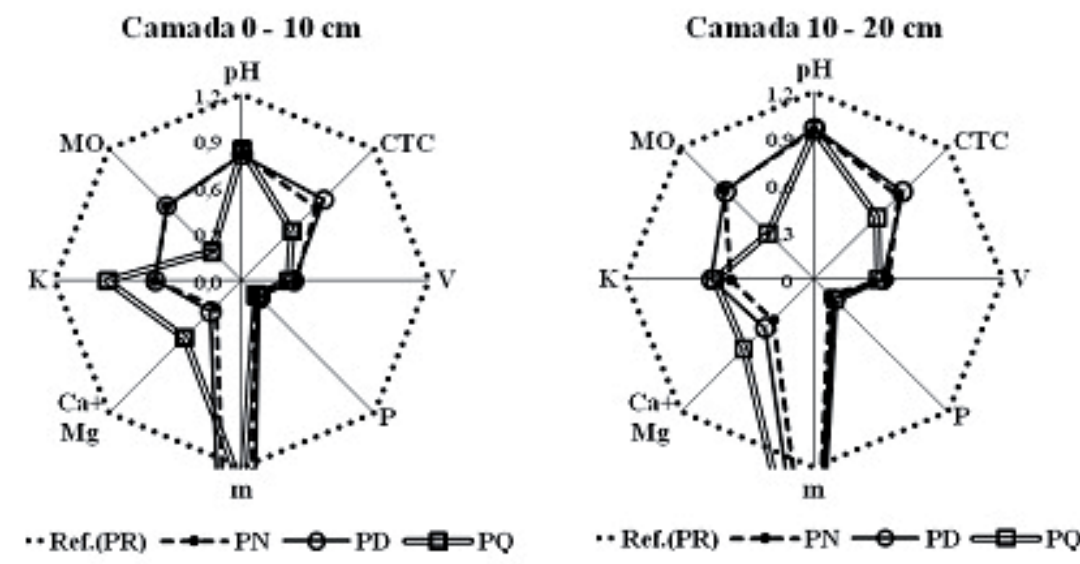

Verifica-se que analisando os atributos da fertilidade do solo nos manejos pastagem pastagem nativa com queimada a cada dois anos, pastagem

formada por uma mistura de espécies nativas com Brachiaria decumbens e queimada a cada três anos e pastagem nativa com queimadas anuais 
para a camada $0-10 \mathrm{~cm}$, somente a saturação por alumínio ultrapassou aos valores encontrados na referência (pastagem de Brachiaria decumbens, sem uso de queimada), enquanto os demais atributos analisados ficaram abaixo dos valores determinados no manejo pastagem de Brachiaria decumbens, sem uso de queimada, ou seja, nenhum desses manejos foi melhor que a referência. Além disso, verifica-se que os manejos pastagem nativa com queimada a cada dois anos e pastagem formada por uma mistura de espécies nativas com Brachiaria decumbens e queimada a cada três anos apresentaram resultados quanto aos atributos analisados absolutamente iguais, enquanto no manejo pastagem nativa com queimadas anuais se destaca em relação aos manejos pastagem nativa com queimada a cada dois anos e pastagem formada por uma mistura de espécies nativas com Brachiaria decumbens e queimada a cada três anos, com um aumento do teor de $\mathrm{K}$, com uma melhora nos teores de $\mathrm{Ca}+\mathrm{Mg}$, com uma menor saturação em alumínio (valor bem próximo do valor encontrado na referência), porém com uma redução do teor de MO e CTC nessa camada considerada $(0-10 \mathrm{~cm})$. Portanto, esses resultados, quando analisados em conjunto indicam que tanto faz usar o manejo pastagem nativa com queimada a cada dois anos, como o manejo pastagem formada por uma mistura de espécies nativas com Brachiaria decumbens e queimada a cada três anos, que os resultados finais quanto à fertilidade do solo serão iguais, enquanto o uso do manejo pastagem nativa com queimadas anuais, embora não tenha sido tão eficiente quanto ao manejo referência (pastagem de Brachiaria decumbens, sem uso de queimada), melhorou a quantidade dos nutrientes $\mathrm{K}, \mathrm{Ca}$ e $\mathrm{Mg}$ no solo, mas com redução considerada do teor de $\mathrm{MO}$, a qual tem importante papel no fornecimento de nutrientes e na melhoria das propriedades físicas do solo, como já relatado anteriormente.

Para a camada de solo de $10-20 \mathrm{~cm}$, verifica-se (Figura 3) que somente a saturação por alumínio, nos manejos pastagem nativa com queimada a cada dois anos, pastagem formada por uma mistura de espécies nativas com Brachiaria decumbens e queimada a cada três anos e pastagem nativa com queimadas anuais ultrapassou aos valores encontrados na referência (pastagem de Brachiaria decumbens, sem uso de queimada), enquanto os demais atributos analisados ficaram abaixo dos valores determinados no manejo pastagem de Brachiaria decumbens, sem uso de queimada, ou seja, nenhum desses manejos foi melhor que a referência para esta camada de solo, como já foi mostrado para a camada de $0-10 \mathrm{~cm}$. Além disso, verifica-se novamente como na camada de $0-10 \mathrm{~cm}$ que os manejos pastagem nativa com queimada a cada dois anos e pastagem formada por uma mistura de espécies nativas com Brachiaria decumbens e queimada a cada três anos apresentaram resultados quanto aos atributos analisados iguais, enquanto no manejo pastagem nativa com queimadas anuais se destaca apenas, em relação aos manejos pastagem nativa com queimada a cada dois anos e pastagem formada por uma mistura de espécies nativas com Brachiaria decumbens e queimada a cada três anos, com uma melhora nos teores de $\mathrm{Ca}+\mathrm{Mg}$, porém com uma redução do teor de MO e CTC nessa camada considerada $(0-10 \mathrm{~cm})$ indicando que o efeito do fogo usado anualmente afetou a MO e CTC além dos $10 \mathrm{~cm}$ de profundidade, persistindo então o problema quanto aos baixos teores de MO no solo.

Esses resultados mostraram que nesses sistemas extrativistas de manejo (baixo nível tecnológico), o uso da Brachiaria decumbens, sem queimas anuais ou esporádicas, com adubação e calagem esporádica (como presente trabalho feitas a cada quatro anos) representa maiores benefícios para o solo/pastagem representando melhor qualidade química do solo. Por outro lado, os manejos pastagem nativa com queimada a cada dois anos e pastagem formada por uma mistura de espécies nativas com Brachiaria decumbens, onde são feitas queimadas a cada três anos, degradaram menos o teor de MO nas profundidades analisadas em relação ao manejo pastagem nativa com queimadas anuais, que é o sistema mais comum na região de estudo onde 
queima anual constitui-se em uma prática largamente adotada e defendida por causa do baixo custo operacional de limpeza da pastagem em substituição à roçagem, bem como para controlar de pragas e renovação das partes vegetativas não consumidas e lignificadas do extrato herbáceo, provocando um rebrote de melhor qualidade e controle do crescimento de arbustos, como relatado por Barroso Filho (2007). Entretanto, não se pode negligenciar que, se de um lado a queimada anual facilita a vida de parte dos agricultores trazendo benefícios em curto prazo, de outro, ela afeta negativamente a biodiversidade (afeta os microorganismos do solo e elimina os insetos inimigos naturais das pragas), a dinâmica dos ecossistemas, aumenta o processo de erosão do solo, deteriora a qualidade do ar e provoca danos ao patrimônio público e privado, prejudicando o produtor a médio e longo prazo e à sociedade como um todo (LOUZADA; MACHADO; BERG, 2003; BARROSO FILHO, 2007), reduzindo o teor de matéria orgânica do solo. O qual, como mostrado neste trabalho, pode ser visto como um atributo chave quando se pretende avaliar a fertilidade do solo, uma vez que tem importante papel no fornecimento de nutrientes e na melhoria das propriedades físico-hidricas e químicas do solo (BERNOUX et al., 1999; DONKOR et al., 2002).

Portanto, se o manejo extrativista, com baixo nível tecnológico e uso da queimada é a prática mais difundida na região, porque não, num primeiro momento, buscar a difusão dos manejos pastagem nativa com queimada a cada dois anos ou pastagem formada por uma mistura de espécies nativas com Brachiaria decumbens e queimada a cada três anos, que pelo menos afetam menos o teor de MO do solo, que, segundo Schaefer et al. (2002) a degradação do solo, a baixa produção de matéria seca e a degradação das pastagens ocorrem proporcionalmente com a perda de matéria orgânica do solo, em relação ao manejo pastagem nativa com queimadas anuais. Dessa forma, embora o manejo pastagem nativa com queimadas anuais seja o preferido e mais econômico do ponto de vista dos agricultores, deve ser substituído, por alternativas possíveis, tanto economicamente quanto ambientalmente, para a realidade da região.

\section{Conclusões}

Dentre os manejos estudados:

- o manejo pastagem de Brachiaria decumbens foi o que apresentou os melhores resultados quanto aos atributos de solo analisados;

- os manejos de pastagem nativa com queimada a cada dois anos, e manejo de pastagem formada por uma mistura de espécies nativas com Brachiaria decumbens e queimada a cada três anos, não apresentaram diferenças quanto aos atributos de solo analisados;

- o manejo pastagem nativa com queimadas anuais provocou os menores valores de matéria orgânica.

\section{Referências}

BARROSO FILHO, J. Sistemas silvopastoris: opção à queima do pasto e da floresta, em 04/09/2007. Disponível em: $<$ http://portalamazonia.globo.com>. Acesso em: 12 nov. 2007.

BERNOUX, M.; FEIGL, B. J.; CERRI, C. C.; GERALDES, A. P. A.; FERNANDES, S. A. P. Carbono e nitrogênio em solo de uma cronosseqüência de floresta tropical- pastagem de Paragominas. Scentia Agricola, Piracicaba, SP, v. 56, n. 4, p. 777-783, 1999.

BONFIM SILVA, E. M. Nitrogênio e enxofre na recuperação de pastagem de capim Braquiária em degradação em Neossolo quartzarênico com expressiva matéria orgânica. Disponível em: <http://www.teses.usp. br/teses/disponiveis/11/11140/tde-29112005-161725/>. Acesso em: 09 nov. 2009.

DONKOR, N. T.; GEDIR, J. V.; HUDSON, R. J.; BORK, E. W.; CHANASYK, D. S.; NAETH, M. A. Impacts of grazing systems on soil compaction and pasture production in Alberta. Canadian Journal of Soil Science, Ontário, v. 82, n. 1, p. 1-8, 2002.

EMPRESA BRASILEIRA DE PESQUISA AGROPECUÁRIA - EMBRAPA. Manual de métodos de análise de solo. 2. ed. Rio de Janeiro: EMBRAPA, 1997. 
FERNANDES, A. H. B. M.; FERNANDES, F. A. Características químicas do solo em área de pastagem nativa recém queimada no Pantanal arenoso, MS. Corumbá: Embrapa Pantanal, 2002. 18 p. (Embrapa Pantanal. Boletim de Pesquisa e Desenvolvimento, 36).

FERNANDEZ, I.; CABANEIRO, A.; CARBALLAS, T. Organic matter changes immediately after a wild-fire in Atlantic Forest soil and comparison with laboratory soil heating. Soil Biology e Biochemistry, Oxford, v. 29, n. 1, p. 1-11, 1997.

FERREIRA, R. R. M.; TAVARES FILHO, J.; FERREIRA, V. M. Efeitos de sistemas de manejo de pastagens nas propriedades físicas do solo. Semina: Ciências Agrárias, Londrina, v. 31, n. 4, p. 913-932, out./dez. 2010.

GASSEN, D. N.; KOCHHANN, R. A. Benefícios de insetos de solo sob plantio direto In: NUERNBERG, N. J. (Ed.). CONCEITOS E FUNDAMENTOS DO SISTEMA PLANTIO DIRETO, 1998, Lages. Anais... Lages: SBCS/NRS, 1998. p. 151-160.

GIOVANNINI, G.; LUCCHESI, S. Modifications induced in soil physical-chemical parameters by experimental fires at different intensities. Soil Science, Ottawa, v. 162, n. 7, p. 479-486, 1997.

HERINGER, I.; JACQUES, A. V. A.; BISSANI, C. A.; TEDESCO, M. Características de um Latossolo Vermelho sob pastagem natural sujeita à ação prolongada do fogo e de práticas alternativas de manejo. Ciência Rural, Santa Maria, v. 32, n. 2, p. 309-314, 2002.

HORTA, I. de M. F. Levantamento dos solos e ocupação da superficie do Município de Nazareno, MG. Disponível em: $\quad<$ http://bibtede.ufla.br/tede//tde_busca/arquivo. php?codArquivo=159>. Acesso em: 15 out. 2009.

LOUZADA, J. N. C.; MACHADO, F. S.; BERG, E. V.D. O fogo como instrumento de manejo em agroecossistemas. Informe Agropecuário, Belo Horizonte, MG, v. 24, n. 220, p. 29-36, 2003.

MARQUES, J. J. G. S. M.; CURI, N.; LIMA, J. M. Recursos ambientais da Bacia do Alto Rio Grande, Minas Gerais. 2002. Especialização (Solos e Meio Ambiente) Universidade Federal de Lavras. Fundação de Apoio ao Ensino, Pesquisa e Extensão, Lavras.

MÜlleR, M. M. L.; GUIMARÃES, M. F.; DESJARDINS, T.; MARTINS, P. F. S. Degradação das pastagens na Região Amazônica: propriedades físicas do solo e crescimento das raízes. Pesquisa Agropecuária Brasileira, Brasília, v. 36, n. 11, p. 1409-1418, 2001.

PIETIKÄINEN, J.; FRITZE， H. Clear-cutting and prescribed burning in coniferous forest: Comparison of effects on soil fungal and total microbial biomass, respiration activity and nitrification. Soil Biology and Biochemistry, Oxford, v. 27, n. 3, p. 101-109, 1995.

PIVELlO, V. R.; COUTINHO, L. M. Transfer of macronutrients to the atmosphere during experimental burnings in an open cerrado (Brazilian savanna). Journal of Tropical Ecology, Cambridge, v. 8, n. 4, p. 487-497. 1992.

SCHACHT, W. H.; STUBBENDIECK, T.; BRAGG, T. B.; SMART, A. J.; DORAN, J. W. Soil quality response of reestablished grasslands to mowing and burning. Journal of Range Management, Denver, v. 49, n. 5, p. 458-463, 1996.

SCHAEFER, C. E. R.; SILVA, D. D.; PAIVA, K. W. N.; PRUSKI, F. F.; ALBUQUERQUE FILHO, M. R.; ALBUQUERQUE, M. A. Perdas de solo, nutrientes, matéria orgânica e efeitos microestruturais em Argissolo Vermelho-Amarelo sob chuva simulada. Pesquisa Agropecuária Brasileira, Brasília, v. 37, n. 5, p. 669-678. 2002.

STECKLING, C.; ERNANI, P. R. Rendimento de massa seca de milho em função do método de aplicação de fontes de fósforo e do $\mathrm{pH}$ do solo. In: REUNIÃO SULBRASILEIRA DE CIÊNCIA DO SOLO, 2., 1998, Santa Maria. Anais... Santa Maria: SBCS, 1998. p. 161-162. 